\title{
The corrosion of dental amalgam in artificial salivas: an electrochemical impedance study
}

\author{
Christopher M.A. Brett *, Florin Trandafir \\ Departamento de Química, Universidade de Coimbra, Largo D. Dinis, 3004-535 Coimbra, Portugal \\ Received 4 July 2003; received in revised form 9 January 2004; accepted 13 January 2004 \\ Available online 26 February 2004
}

\begin{abstract}
An electrochemical impedance study of the corrosion of Tytin dental amalgam was carried out in electrolytes similar to artificial saliva with or without lactic acid, and in standard inorganic artificial saliva with higher ionic concentration. Spectra were recorded in the presence and absence of dissolved oxygen to show the importance of the formation of oxide film and the adsorption of the organic component, as well as the exposed surface microstructure. The data, supported by open circuit potential and polarisation curve experiments, obtained in the presence and absence of dissolved oxygen are interpreted in the light of possible corrosion mechanisms.
\end{abstract}

(C) 2004 Elsevier B.V. All rights reserved.

Keywords: Dental amalgam corrosion; Electrochemical impedance; Artificial saliva

\section{Introduction}

The corrosion and wear resistance of dental amalgams has been of much interest in recent years as a result of increased concern regarding toxicity arising from amalgam particles and corrosion products in the oral cavity. A further concern results from the possible release of mercury and mercury vapour [1-4] as well as the effect that mercury can have on antioxidant activity [5] and neurotoxicological effects [6].

A number of factors can influence the rate of corrosion. These include acidity of the contacting medium and temperature, which can both undergo sharp variations in a short period of time in the oral cavity, as well as the effective potential of the amalgam $[7,8]$. For these reasons, a full understanding of the electrochemical and corrosion behaviour of the amalgams can be of much benefit in taking appropriate measures to reduce amalgam corrosion as well as ensuring complete amalgamation such that there is no free mercury that can be vapourised.

\footnotetext{
${ }^{*}$ Corresponding author. Tel./fax: +351-239-835295.

E-mail address: brett@ci.uc.pt (C.M.A. Brett).
}

Dental amalgam is formed by the rapid reaction of liquid mercury with a powder alloy containing principally silver $(40-70 \%)$, tin $(15-30 \%)$ and copper (10$30 \%$ ). Mercury diffuses into the alloy particles and reacts with silver, tin and copper, forming various compounds. The exact compounds formed depend on the chemical composition of the powder and on particle shape (which can be spherical or irregular) but are mainly phases of the systems $\mathrm{Sn}-\mathrm{Hg}, \mathrm{Ag}-\mathrm{Hg}$, with $\mathrm{Ag}-\mathrm{Cu}$ and $\mathrm{Ag}-\mathrm{Sn}$ phases remaining from the reactants. For the currently used, high copper amalgams, the main reaction is [9]

$$
\begin{aligned}
& \gamma-\mathrm{Ag}_{3} \mathrm{Sn}+\mathrm{Ag}-\mathrm{Cu}+\mathrm{Hg} \\
& \quad \rightarrow \gamma_{1}-\mathrm{Ag}_{2} \mathrm{Hg}_{3}+\gamma_{2}-\mathrm{Sn}_{7} \mathrm{Hg}+\gamma-\mathrm{Ag}_{3} \mathrm{Sn}+\mathrm{Ag}-\mathrm{Cu} .
\end{aligned}
$$

The $\mathrm{Sn}-\mathrm{Hg}$ phase, which has a relatively low corrosion resistance, then undergoes further reaction, according to

$\gamma_{2}-\mathrm{Sn}_{7} \mathrm{Hg}+\mathrm{Ag}-\mathrm{Cu} \rightarrow \eta^{\prime}-\mathrm{Cu}_{6} \mathrm{Sn}_{5}+\gamma_{1}-\mathrm{Ag}_{2} \mathrm{Hg}_{3}$.

The microstructure of the dental amalgam is complex, consisting of new microphases, as produced in the reactions above, and the remains of the powder alloy particles, within the $\gamma_{1}-\mathrm{Ag}_{2} \mathrm{Hg}_{3}$ matrix phase, as exemplified by Dispersalloy ${ }^{\circledR}[10]$.

For this reason, and in order to understand better the role of the various phases, individual phases have 
recently been fabricated metallurgically following standard recommendations [11] and investigated by electrochemical and surface analysis techniques in $0.9 \%$ sodium chloride. The immersion time was varied and the influence of applied potential investigated by electrochemical impedance and electrochemical noise techniques. These studies showed clearly that some of the phases undergo corrosion more easily than others and that in $0.9 \%$ sodium chloride the $\gamma_{1}-\mathrm{Ag}_{2} \mathrm{Hg}_{3}$ phase is clearly that which is most affected. Comparison has been made with the corrosion behaviour of dental amalgams $[10,12,13]$. Proper correlation of the behaviour with that of real, complex dental amalgams where grain boundary effects, voids, and so forth are additional factors, remains a challenge.

Some comparisons of the corrosion rates of different amalgams have been made in the literature using mainly open circuit potential measurements, polarisation curves and cyclic voltammetry [14-16]. The effect of the bathing solution on corrosion rate has not been extensively investigated and, with the rare exception of [17], has only recently begun to be studied $[18,19]$. There are large numbers of possible solutions, which have been used to simulate body fluids in these studies, particularly those similar to saliva and to physiological serum. This variety has been recognised and compiled [20,21], but it does make comparisons between results in the literature in different bathing solutions difficult.

Electrochemical impedance spectroscopy (EIS) can be particularly powerful for helping in the interpretation of the electrochemical behaviour of complex interfacial processes and complex materials, and has already been applied to the investigation and analysis of the processes occurring at the surface of individual amalgam phases $[10,12]$. In this study EIS has been used to investigate the electrochemical behaviour of Tytin ${ }^{\circledR}$ FC amalgam in different bathing solutions. Tytin ${ }^{\circledR}$ is a high-copper amalgam, the powder alloy consisting of spherical particles. After mixing with mercury, it has a mercury-toalloy ratio of approximately $43 \%$ by weight. The bathing solutions employed were the artificial saliva used in previous studies [19], the concentration of the organic component, lactic acid, being varied, and a standard solution, AFNOR S90-701 [22], which has a higher ionic concentration but no organic component.

\section{Experimental}

\subsection{Electrodes and instrumentation}

Tytin ${ }^{\circledR}$ FC dental amalgam (KerrDental, USA) in two-part plastic capsules separated by a membrane, one part with mercury and the other with the powder alloy, were mixed in a mechanical vibrator after squeezing the capsule to break the membrane. The powder alloy composition of Tytin ${ }^{\circledR}$ is $59 \%$ silver, $28 \%$ tin and $13 \%$ copper, with a mercury-to-alloy ratio of approximately $43 \%$. It was immediately cast into cylinder-shaped pieces of diameter $\sim 0.6 \mathrm{~cm}$ and depth $\sim 3 \mathrm{~mm}$.

Amalgam pieces were made into electrodes in the following way. A copper wire was fixed to one face of the sample with flash-dry silver paint (SPI). When dry, this face, together with the edges, was covered with a layer of Araldite $^{\circledR}$ (Ciba-Geigy, Switzerland) epoxy-resin adhesive and dried again for at least $24 \mathrm{~h}$, leaving just one face exposed. Surface preparation consisted of polishing with dry SiC paper down to 1200 grit and then with alumina foil of 25,3 , and $0.3 \mu \mathrm{m}$ particle size until a smooth mirror-like finish was obtained. The metallic surface was polished with alumina foil as necessary between experiments. The exposed electrode area was $0.28 \mathrm{~cm}^{2}$.

A three-electrode system used for the electrochemical experiments included an $\mathrm{Ag}|\mathrm{AgCl}| 3 \mathrm{M} \mathrm{KCl}$ electrode as the reference and a Pt foil auxiliary electrode.

Experiments were carried out using an Autolab PGSTAT 10 with a FRA2 module (Ecochemie, Netherlands) controlled by FRA 4.7 software for impedance measurements and GPES 4.7 software for open circuit potential and polarisation curve measurements. FRA and GPES software was used also for data analysis. Impedance spectra were recorded at the open circuit potential from $65 \mathrm{kHz}$ down to 0.1 $\mathrm{Hz}$, five steps per frequency decade with a sinusoidal perturbation of $5 \mathrm{mV} \mathrm{rms}$.

\subsection{Bathing solutions}

Two types of bathing solution were employed: an artificial saliva as used previously [19], with varying concentrations of lactic acid (in order to investigate the importance of the organic compound (lactic acid) in artificial saliva) and AFNOR S90-701 standard solution [22].

Preparation of 11 of each of the solutions in which the electrodes were immersed was as follows:

1. Artificial saliva (AS) contains $1.5 \mathrm{~g} \mathrm{KCl}, 1.5 \mathrm{~g}$ $\mathrm{NaHCO}_{3}, 0.5 \mathrm{~g} \mathrm{NaH}_{2} \mathrm{PO}_{4}, 0.5 \mathrm{~g} \mathrm{KSCN}$ and, under standard conditions, $0.9 \mathrm{~g}$ lactic acid. The amount of lactic acid was varied from 0 up to $1.5 \mathrm{~g}^{-1}$ in steps of $0.3 \mathrm{gl}^{-1}$.

2. AFNOR standard S90-701 [21] (designated as AFNOR in this paper) contains $0.26 \mathrm{~g} \mathrm{Na}_{2} \mathrm{HPO}_{4}, 6.7 \mathrm{~g}$ $\mathrm{NaCl}, 0.33$ g KSCN, $0.2 \mathrm{~g} \mathrm{KH}_{2} \mathrm{PO}_{4}, 1.5 \mathrm{~g} \mathrm{NaHCO}_{3}$ and $1.2 \mathrm{~g} \mathrm{KCl}$.

The corresponding molar concentrations are given in Table 1.

All solutions were prepared using Milli-Q ultrapure water of resistivity $>18 \mathrm{M} \Omega \mathrm{cm}$ and analytical grade reagents. The laboratory temperature was $25 \pm 1{ }^{\circ} \mathrm{C}$ in all experiments. 
Table 1

Concentrations of dental amalgam bathing solution components

\begin{tabular}{lcc}
\hline \multirow{2}{*}{ Component } & \multicolumn{2}{c}{ Concentration $(\mathrm{mM})$} \\
\cline { 2 - 3 } & Artificial saliva & AFNOR S90/071 \\
\hline $\mathrm{Cl}^{-}$ & 20.0 & 130.8 \\
$\mathrm{HCO}_{3}^{-}$ & 17.9 & 5.95 \\
$\mathrm{SCN}^{-}$ & 5.15 & 3.40 \\
$\mathrm{HPO}_{4}^{-} / \mathrm{H}_{2} \mathrm{PO}_{4}^{2-}$ & 4.17 & 3.30 \\
$\mathrm{Na}^{+}$ & 22.0 & 124.3 \\
$\mathrm{~K}^{+}$ & 25.3 & 21.0 \\
Lactic acid & 4.95 & - \\
\hline
\end{tabular}

\section{Results and discussion}

Electrochemical impedance measurements can lead to an improved understanding of the processes that take place at the amalgam electrode surface as well as the influence of surface oxide. This strategy has previously been used for single phases $[10,13]$. An additional factor, which can be probed by EIS, relates to differences in the exposed microphase structure and grain boundaries between samples of dental amalgam. This can lead to some variation in the electrochemical results obtained, which was recently recognised in the evaluation of a proposed potentiostatic corrosion test [23]. Thus, since one of the most important processes is the formation of oxide on the surface, experiments were carried out in the presence and absence of oxygen and also on different amalgam samples.

\subsection{Open circuit potential and polarisation curves}

In Fig. 1 is shown the variation of open circuit potential (ocp) with time, from which several deductions can be made. The first is that the initial potential in artificial saliva is more negative $(-0.28 \mathrm{~V}$ vs. $\mathrm{Ag} \mid \mathrm{AgCl})$ than that in AFNOR ( $-0.17 \mathrm{~V}$ vs. $\mathrm{Ag} \mid \mathrm{AgCl})$. This could be due to the mixed potential resulting from the ionic constitution of the solutions (see Table 1). Secondly, in the absence of oxygen, there is an initial variation of the potential in a negative direction, before oxide formation commences, typical of active corrosion. The steady-state open circuit potentials are very similar for AS and AFNOR solutions $--0.05 \mathrm{~V}$ in the presence of oxygen and $-0.13 \mathrm{~V}$ vs. $\mathrm{Ag} \mid \mathrm{AgCl}$ in its absence. This may appear surprising given the different constitutions of the bathing solutions. However, their $\mathrm{pH}$ is the same and this suggests that the surface oxide film, once formed, must have a very similar composition. It should be noted, however, that the steady-state potential varies with $\mathrm{pH}$ and in the case of artificial saliva, there is evidence of adsorption of lactic acid molecules at lower $\mathrm{pH}$ impeding oxide formation [19].

The polarisation curves, Fig. 2, show that corrosion currents do not differ significantly between the two bathing solutions and the currents are generally higher
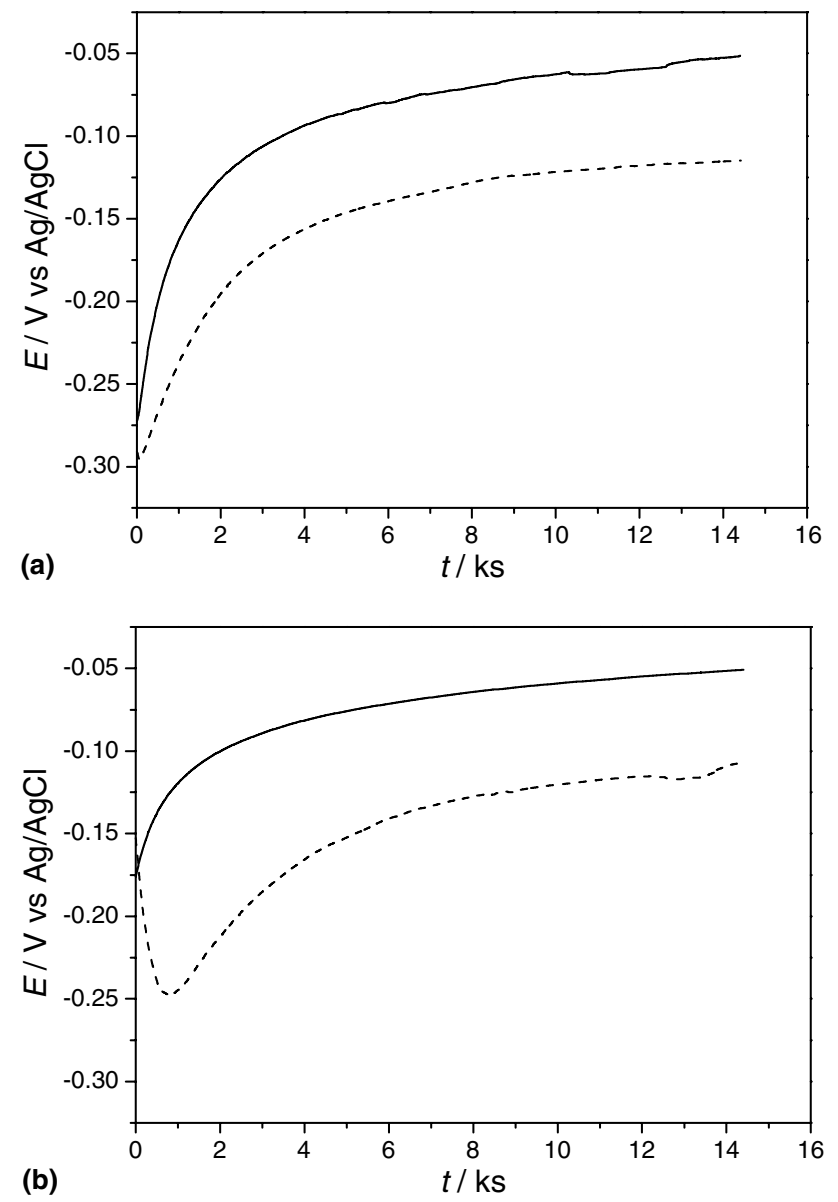

Fig. 1. Variation of open circuit potential with time for Tytin dental amalgam immersed in (a) artificial saliva and (b) AFNOR solution: (-) aerated solution, (- - - -) deaerated solution.

in the absence of oxygen, particularly at potentials corresponding to anodic polarisation. The current peak appearing at $0.2 \mathrm{~V}$ vs. $\mathrm{Ag} \mid \mathrm{AgCl}$, particularly in AFNOR, is probably due to tin oxide formation and has been noted previously with amalgams [10]. Currents are also higher in AFNOR as expected because of its higher chloride concentration. In the zone of the corrosion potential, the differences between the various experimental conditions are less accentuated.

As a result of these experimental data, it was decided to record spectra at the ocp and only after a minimum immersion time of $4 \mathrm{~h}$.

\subsection{Impedance spectra in artificial saliva}

Most impedance results to be presented and discussed derive from the same sample of dental amalgam. Each of these experiments was carried out three times to ensure reproducibility, after polishing to expose a fresh, non-oxidised surface each time. To bring out the fact that the behaviour depends on the sample, as mentioned above, results of experiments carried out in artificial saliva with different amounts of lactic acid from 0 up to 

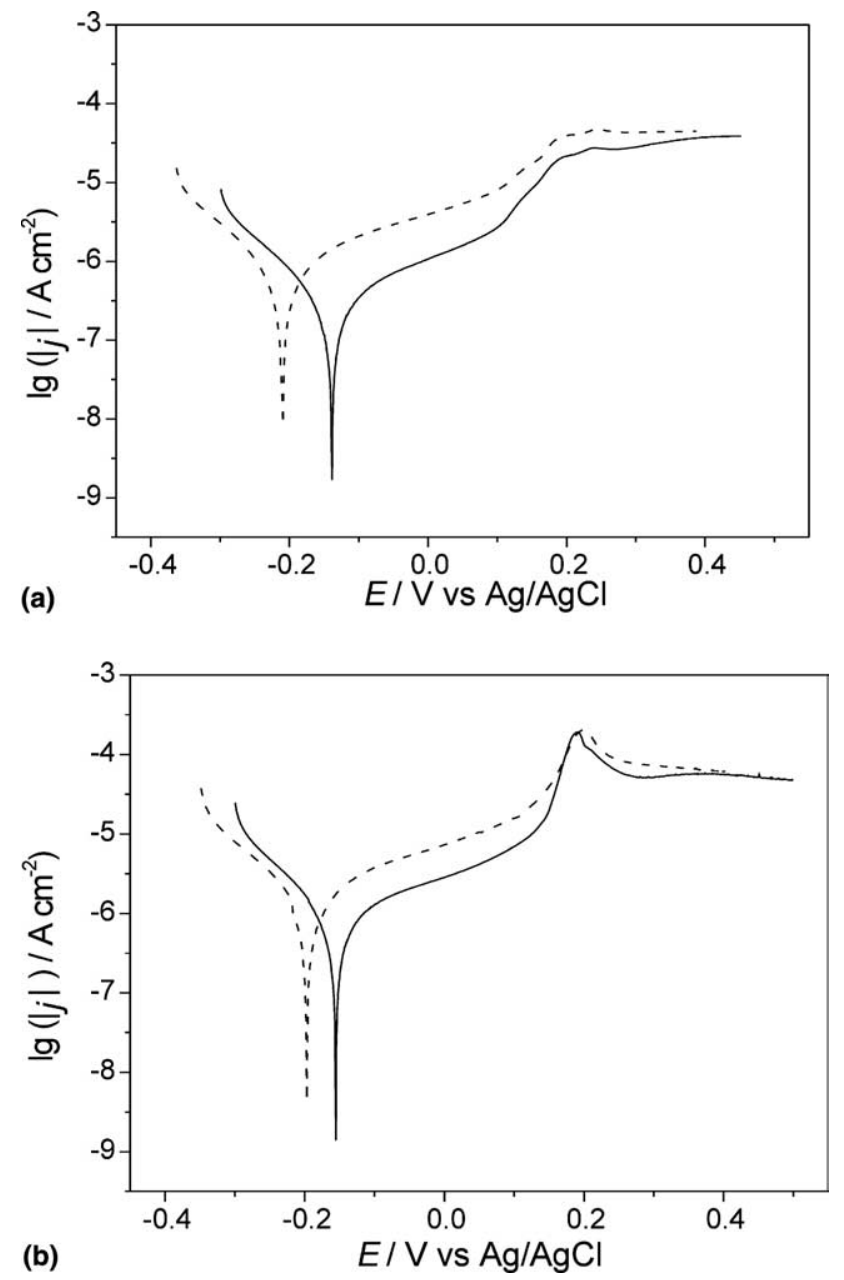

Fig. 2. Polarisation curves for Tytin dental amalgam after $4 \mathrm{~h}$ immersion in (a) artificial saliva and (b) AFNOR solution: (-) aerated solution, (- - - ) deaerated solution. Scan rate $2 \mathrm{mV} \mathrm{s}^{-1}$.

$1.5 \mathrm{gl}^{-1}$ in aerated solution are shown for two different samples in Figs. 3 and 4. Various samples were tested and Fig. 4 represents an extreme case of differences between samples. Apart from this, it becomes clear that the Bode representation of the spectra is more appropriate for visualisation of the experimental results.

Fig. 5 shows spectra from the same sample as depicted in Fig. 3 in the absence of oxygen. There is a significant reduction in the absolute values of the impedance on removal of oxygen from the solution. Also, the relative influence of lactic acid on the spectra is noticeably more in the presence of dissolved oxygen. It has been shown recently that lactic acid itself can influence the rate of corrosion in the initial stages through adsorption on the surface, in this way impeding oxide formation [19].

Fitting of the impedance spectra was done with an equivalent circuit using a series combination of the cell resistance, $R_{\Omega}$, with two RC parallel combinations, each composed of a resistance, $R$, and a constant phase element (CPE) modelled by the FRA software as a non-
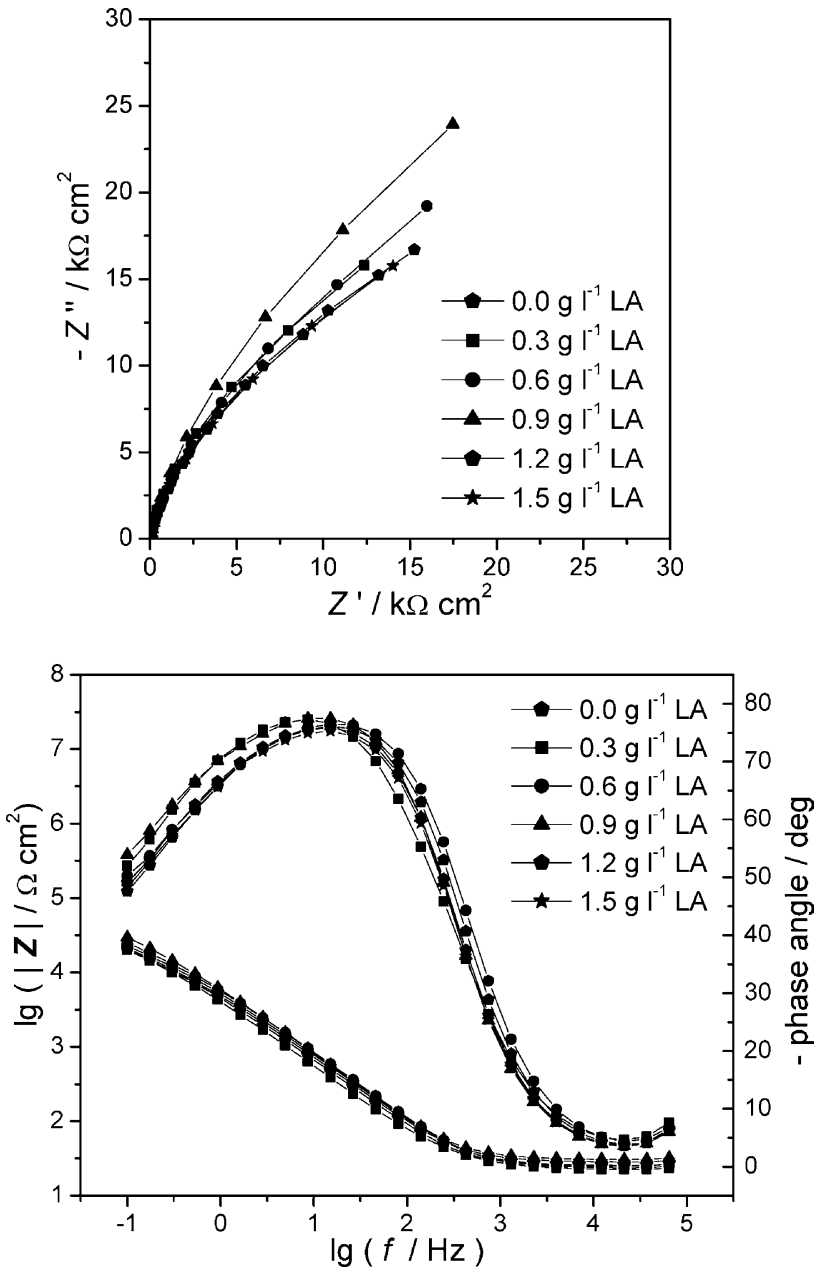

Fig. 3. Impedance spectra for Tytin dental amalgam immersed in artificial saliva with varying concentrations of lactic acid from 0 up to 1.5 $\mathrm{gl}^{-1}$.

ideal capacitor according to $\operatorname{CPE}=\left\{(\mathrm{Ci} \omega)^{\alpha}\right\}^{-1}$. The $\mathrm{CPE}$ was found to be necessary because of the microscopic roughness of the electrode, expressed through the exponent $\alpha$. This is the same model that was found to be appropriate in corrosion studies of the individual phases [13]. The physical meaning given to the circuit is association with the oxide|metal interface $\left(R_{1} \mathrm{CPE}_{1}\right)$ and with the oxide layer formed on the surface $\left(R_{2} \mathrm{CPE}_{2}\right)$. Other combinations of resistances and capacitances were tried, in particular two RCPE elements in parallel, to model the corrosion of different phases exposed to solution at the amalgam surface - none of these were found to give a satisfactory fit.

The values of the adjusted parameters are given in Table 2.

In aerated solution, there is some evidence for a maximum value of charge transfer resistance $\left(R_{1}\right)$ with $0.9 \mathrm{~g}^{-1}$ lactic acid, although, in the absence of oxygen, this does not occur and the values are, on average, slightly lower, consistent with the indirect effect of a thinner oxide film on the surface. Capacitance values 

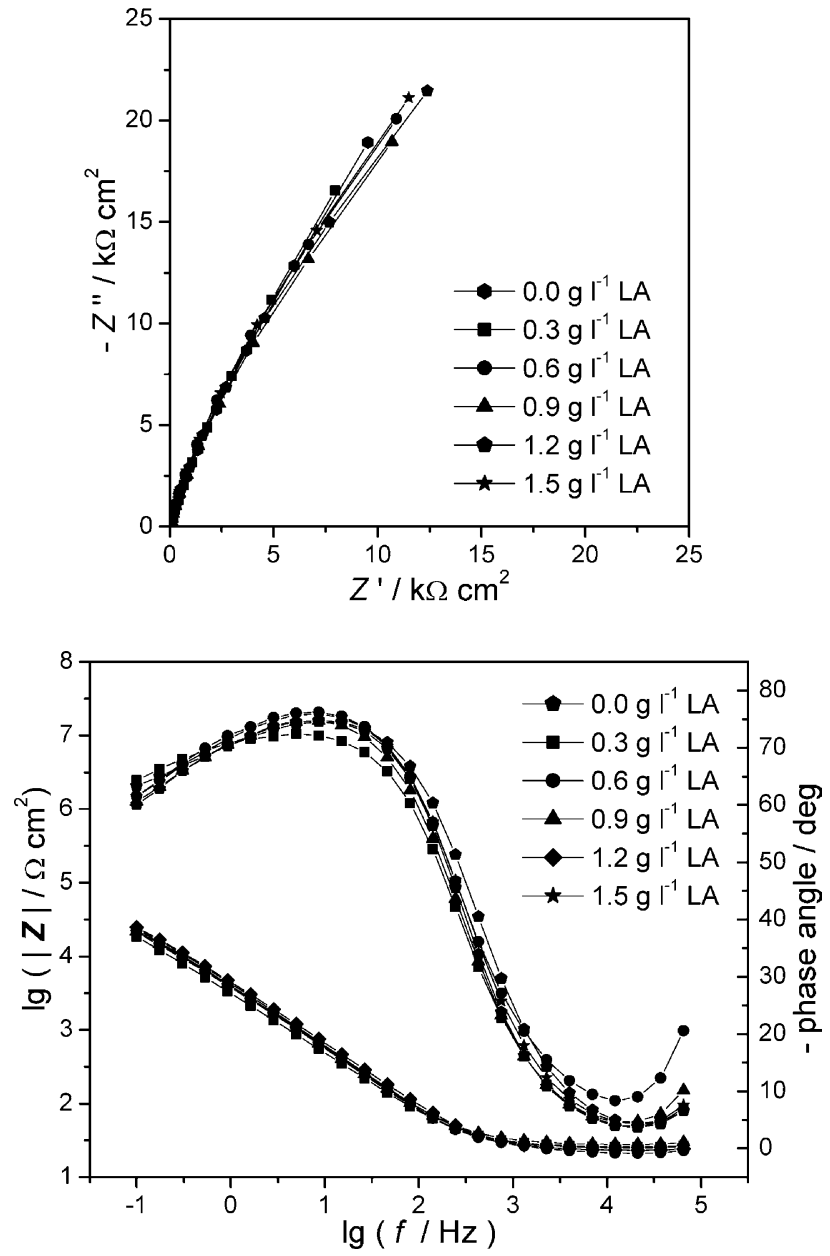

Fig. 4. Impedance spectra for a second sample of Tytin dental amalgam immersed in artificial saliva with varying concentrations of lactic acid from 0 up to $1.5 \mathrm{gl}^{-1}$.

associated with the charge transfer process are around $12-16 \mu \mathrm{F} \mathrm{cm}^{-2}$ in the presence and absence of oxygen, values similar to individual phases, and the corresponding roughness exponents are more or less constant at around 0.88 , both in the presence and absence of oxygen. The characteristics of the oxide film are reflected in the values of $R_{2}$, which are significantly less in the absence of oxygen, whereas the values of $C_{2}$ and roughness exponent remain similar, being slightly large for the thicker oxide film, suggesting that some smoothing of the surface occurs. The cell resistance is around $25 \mathrm{~cm}^{2}$ for all concentrations of lactic acid both in aerated and deaerated solution.

\subsection{Impedance spectra in AFNOR}

Some impedance spectra for AFNOR are presented in Fig. 6. In this case, with fixed chemical composition, the variation of the impedance over time is also shown in the presence of dissolved oxygen; and for $4 \mathrm{~h} \mathrm{im-}$ mersion in the absence of oxygen. At long immersion times (more than $48 \mathrm{~h}$ ), the difference between behaviour
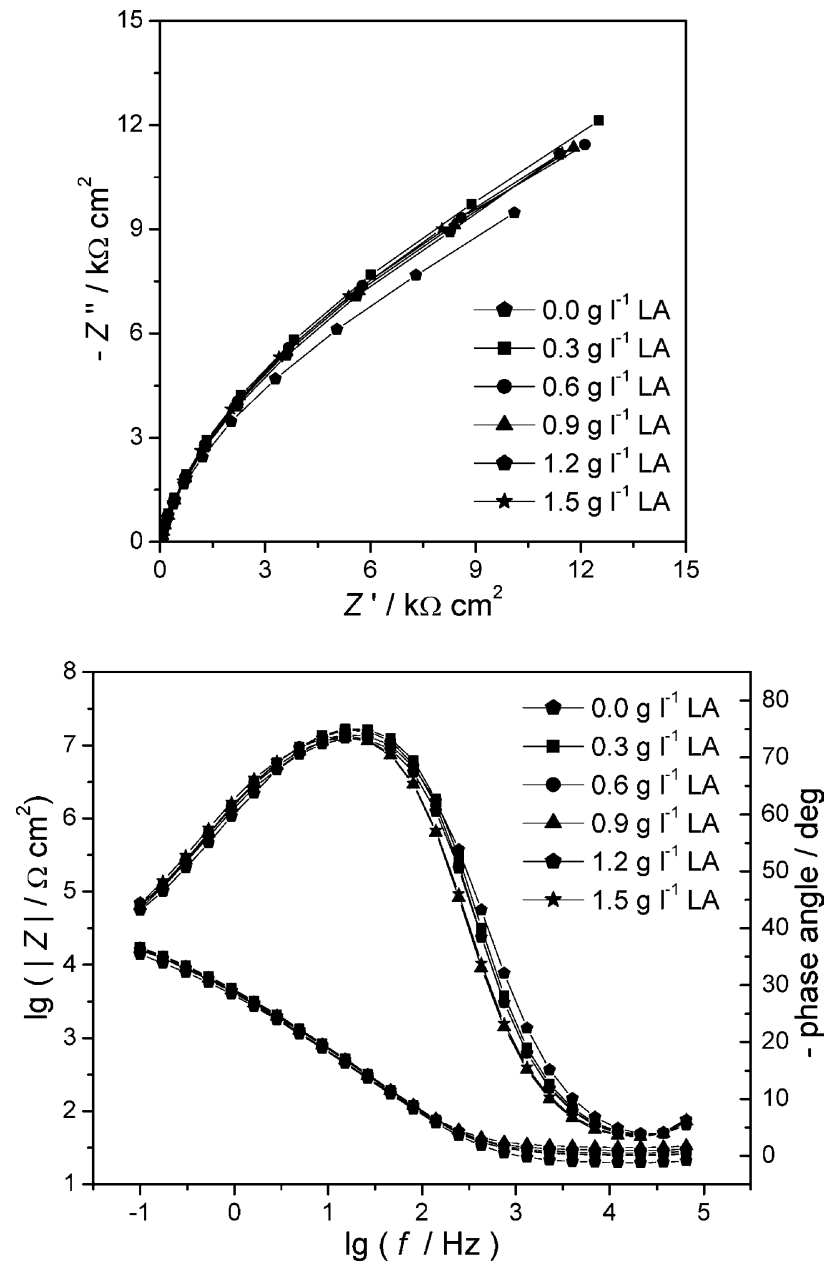

Fig. 5. Impedance spectra for Tytin dental amalgam immersed in deaerated artificial saliva with varying concentrations of lactic acid from 0 up to $1.5 \mathrm{gl}^{-1}$.

in solutions with and without oxygen removal becomes smaller, as expected, owing to the trace of dissolved oxygen still remaining (data not shown). The same occurs in artificial saliva at long immersion times.

As can be seen, the forms of the impedance spectra appear different from those in artificial saliva and at low frequency tend towards a straight line that is almost $45^{\circ}$ in the complex plane representation. This tendency has been noted in studies performed in $0.9 \%$ sodium chloride solution [16]. Therefore, fitting with an electrical equivalent circuit including a Warburg impedance was tried. However, using the same two RCPE in series model as for artificial saliva was found to give a better fit. The results of the fitting are shown in Table 3.

It can be seen that the values of the two resistances $R_{1}$ and $R_{2}$ decrease with increasing immersion time until a steady state is reached after $24-48 \mathrm{~h}$; values are smaller after $4 \mathrm{~h}$ immersion in the absence of oxygen, as would be expected. The values of capacitance decrease slightly with time but the roughness exponents remain the same for $24 \mathrm{~h}$ and longer exposures. Nevertheless, the capacitance 
Table 2

Equivalent circuit analysis of impedance spectra in artificial saliva (data from Figs. 3 and 5)

\begin{tabular}{|c|c|c|c|c|c|c|c|c|}
\hline Artificial saliva & [Lactic acid] $\left(\mathrm{g} \mathrm{l}^{-1}\right)$ & $R\left(\Omega \mathrm{cm}^{2}\right)$ & $R_{1}\left(\mathrm{k} \Omega \mathrm{cm}^{2}\right)$ & $C_{1}\left(\mu \mathrm{F} \mathrm{cm}^{-2}\right)$ & $\alpha_{1}$ & $R_{2}\left(\mathrm{k} \Omega \mathrm{cm}^{2}\right)$ & $C_{2}\left(\mu \mathrm{F} \mathrm{cm}^{-2}\right)$ & $\alpha_{2}$ \\
\hline \multirow[t]{6}{*}{ Aerated } & 0.0 & 25.0 & 5.3 & 16.0 & 0.87 & 41.7 & 27.6 & 0.91 \\
\hline & 0.3 & 29.6 & 5.7 & 12.5 & 0.87 & 40.7 & 28.6 & 0.91 \\
\hline & 0.6 & 23.8 & 6.2 & 12.5 & 0.88 & 54.7 & 21.9 & 0.91 \\
\hline & 0.9 & 30.9 & 7.5 & 13.8 & 0.88 & 71.5 & 25.1 & 0.93 \\
\hline & 1.2 & 25.5 & 5.9 & 13.7 & 0.88 & 43.9 & 23.6 & 0.91 \\
\hline & 1.5 & 28.5 & 5.5 & 14.0 & 0.87 & 42.8 & 24.9 & 0.91 \\
\hline \multirow[t]{6}{*}{ Deaerated } & 0.0 & 19.7 & 4.5 & 12.7 & 0.87 & 25.4 & 29.0 & 0.88 \\
\hline & 0.3 & 24.9 & 4.7 & 13.6 & 0.89 & 30.2 & 27.3 & 0.90 \\
\hline & 0.6 & 25.4 & 4.4 & 14.6 & 0.89 & 28.0 & 27.1 & 0.90 \\
\hline & 0.9 & 32.0 & 4.6 & 13.2 & 0.88 & 28.7 & 27.5 & 0.90 \\
\hline & 1.2 & 26.7 & 4.6 & 12.2 & 0.87 & 29.3 & 26.2 & 0.89 \\
\hline & 1.5 & 29.1 & 4.7 & 14.1 & 0.87 & 28.6 & 29.8 & 0.90 \\
\hline
\end{tabular}

values are higher in deaerated solution, different behaviour from that which occurs in artificial saliva.

\subsection{Discussion and comparative remarks}

Impedance spectra bring out a number of aspects related to dental amalgam characterisation with respect
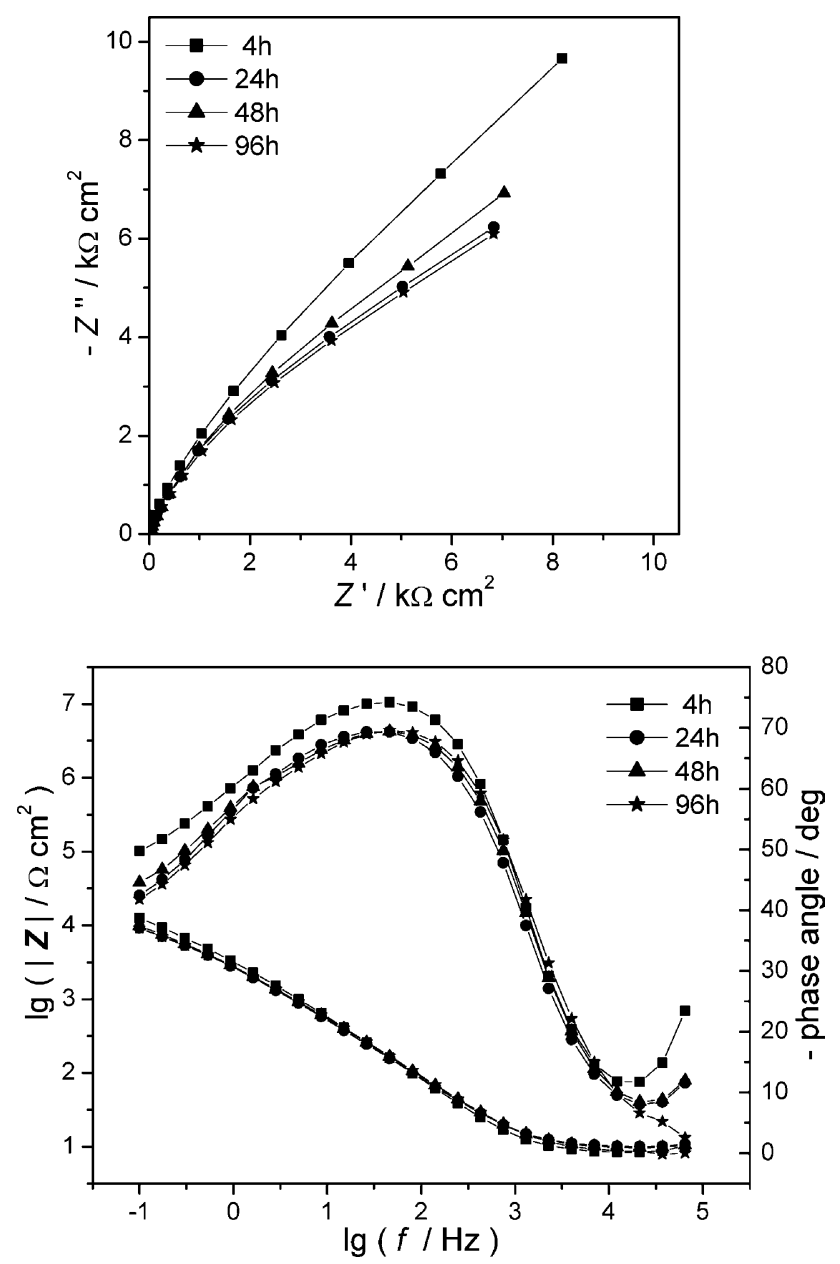

Fig. 6. Impedance spectra for Tytin dental amalgam immersed in AFNOR solution for various periods of time. to the influence of sample surface composition and microstructure, and composition of bathing solution.

Significant effects in the decrease of the impedance magnitude, and thence increase of the corrosion rate, in the absence of dissolved oxygen are seen for both electrolytes. This is much clearer than from other electrochemical techniques such as polarisation curves. For high copper amalgams the unstable corrosion-prone $\mathrm{Sn}-$ $\mathrm{Hg}$ phase should be present only in small amounts and most corrosion occurs from the $\mathrm{Ag}-\mathrm{Hg}$ matrix phase. In the presence of oxygen, there is a tendency for oxide films to form rapidly on the surface, and this is less easy when dissolved oxygen is removed and only trace quantities remain. There is some dealloying of $\mathrm{Ag}-\mathrm{Hg}$, due to mercury oxidation, which then becomes less with time. Interestingly this has little effect, nor does the amount of lactate present in solution, on the measured interfacial capacity in artificial saliva, see Table 2 . The surface roughness is unaffected as would be expected.

However, in AFNOR S90-071, although the corrosion process appears to show some diffusion limitations, i.e. the rates of the surface processes are no longer solely rate-determining, modelling is better achieved by the two-interface model used above for artificial saliva. Between 4 and $24 \mathrm{~h}$ immersion time, the surface becomes slightly rougher (the roughness exponent decreases), which may reflect the formation of loose surface oxide films or of hydroxychloride films, as previously suggested [16], and then reaches steady state behaviour.

In artificial saliva a noticeable increase in the cell resistance occurs when lactic acid is present. This increase is similar in the presence and absence of oxygen. It implies that parts of the amalgam surface are becoming blocked, although not sufficiently to influence the charge transfer resistance, and that corrosion occurs predominantly on other areas of the exposed surface. Taking into account these observations, the conclusion is reached that lactate adsorbs mainly on those microphases not undergoing corrosion, i.e. on $\mathrm{Ag}-\mathrm{Cu}$ or $\mathrm{Cu}-$ $\mathrm{Sn}$ phases. Even so, in deaerated solution, results 
Table 3

Equivalent circuit analysis of impedance spectra in AFNOR solution (data mainly from Fig. 6)

\begin{tabular}{lcllcllll}
\hline Artificial saliva & Immersion time $(\mathrm{h})$ & $R\left(\mathrm{~cm}^{2}\right)$ & $R_{1}\left(\mathrm{k} \mathrm{cm}^{2}\right)$ & $\left.C_{1}(\mu \mathrm{F} \mathrm{cm})^{-2}\right)$ & $\alpha_{1}$ & $R_{2}\left(\mathrm{k} \mathrm{cm}^{2}\right)$ & $\left.C_{2}(\mu \mathrm{F} \mathrm{cm})^{-2}\right)$ & $\alpha_{2}$ \\
\hline Aerated & 4 & 8.1 & 2.58 & 14.6 & 0.86 & 30.4 & 23.6 \\
& 24 & 9.7 & 2.56 & 9.6 & 0.81 & 18.1 & 0.87 \\
& 48 & 9.3 & 2.04 & 10.0 & 0.82 & 20.3 & 16.1 \\
& 96 & 8.1 & 2.09 & 9.3 & 0.82 & 16.8 & 17.4 & 0.83 \\
Deaerated & 4 & 7.0 & 1.95 & 17.8 & 0.86 & 14.3 & 38.4 \\
\hline
\end{tabular}

suggest that there is less competition with any oxide formation and that the blocking is more effective.

The time variation of impedance parameters in AFNOR solution shows corrosion increasing after the initial period and up to $24 \mathrm{~h}$ immersion, with a consequent decrease in charge transfer resistance and interfacial capacity. Solution deaeration again leads to more active corrosion. This has been seen before [24] and a possible explanation is corrosion of copper from $\mathrm{Cu}_{6} \mathrm{Sn}_{5}$, thence exposing $\mathrm{Ag}_{2} \mathrm{Hg}_{3}$ grains, leading to release of some mercury by oxidation. The ionic strength is approximately three times greater and there is no organic component to ameliorate the influence of ionic concentration. Even without lactate, the charge transfer resistance in artificial saliva is higher.

Comparing the $4 \mathrm{~h}$ immersion period with and without dissolved oxygen for AFNOR with the results for artificial saliva, it can be seen that in the former case the influence of oxygen concentration is much larger. Regarding mercury release, it was found that this reached a steady state after $25 \mathrm{~h} \mathrm{[1]}$ and this corroborates results in this work concerning the time variation of the impedance spectra. Indeed, it was found that mercury release is less from Tytin than from other commercial amalgams [7], mercury representing the more dangerous of the possible ionic species resulting from corrosion, and is present in higher amounts in solution [25].

Comparing these artificial body fluids with test solutions containing only chloride ion [16], there is a lower rate of corrosion. This demonstrates that even though the chloride ion is one of the most aggressive ions in these solutions, the other constituents are also determinant in the corrosion behaviour, even for Tytin ${ }^{\circledR}$, which is one of the amalgams leading to lower corrosion rates [1]. Impedance spectra are particularly useful for demonstrating these different contributions.

\section{Conclusions}

This work has shown, particularly through electrochemical impedance spectroscopy, that the observed corrosion behaviour of Tytin ${ }^{\circledR}$ dental amalgam can be dependent on the bathing solution composition as well as on sample identity and exposed surface microstructure. The data obtained in the presence and in the absence of dissolved oxygen have been interpreted in the light of possible corrosion mechanisms, oxide formation and surface adsorption.

\section{Acknowledgement}

The authors thank Dr. Eunice Carrilho for the samples of Tytin ${ }^{\circledR}$ dental amalgam used in this work. The financial support of ICEMS, Coimbra (Research Unit 103 ) is gratefully acknowledged.

\section{References}

[1] M. Marek, J. Dent. Res. 69 (1990) 1167.

[2] M. Marek, Dent. Mater. 13 (1997) 312.

[3] D.B. Mahler, J.D. Adey, L.E. Simms, M. Marek, Dent. Mater. 18 (2002) 407.

[4] T. Okabe, B. Elvebak, L. Carrasco, J.L. Ferracane, R.G. Keanini, H. Nakajima, Dent. Mater. 19 (2002) 38.

[5] M. Pizzichini, M. Fonzi, L. Sugherini, F. Fonzi, A. Gasparoni, M. Comporti, A. Pompella, Sci. Total Environ. 184 (2002) 19.

[6] M. Sweeney, S.L. Creanor, R.A. Smith, R.H. Foye, J. Dentistry 30 (2002) 243.

[7] M. Marek, J. Dent. Res. 76 (1997) 1308.

[8] M. Marek, J. Dent. Res. 72 (1993) 1315.

[9] R.G. Craig, Restorative Dental Materials, Mosby, St. Louis, MO, 1985.

[10] H.A. Acciari, A.C. Guastaldi, C.M.A. Brett, Electrochim. Acta 46 (2001) 3887

[11] American Dental Association Council on Dental Materials and Devices. Specification No.1 for alloy for dental amalgam, J. Am. Dent. Ass. 95 (1977) 1171.

[12] C.M.A. Brett, H.A. Acciari, A.C. Guastaldi, Key Eng. Mat. 230 232 (2002) 463.

[13] H.A. Acciari, A.C. Guastaldi, C.M.A. Brett, Corros. Sci., in press.

[14] B. Westerhoff, M. Darwish, R. Holze, J. Appl. Electrochem. 22 (1992) 1142.

[15] B. Westerhoff, M. Darwish, R. Holze, J. Oral. Rehabil. 22 (1995) 121.

[16] H.A. Acciari, E.N. Codaro, A.C. Guastaldi, Mater. Lett. 36 (1998) 148

[17] R.I. Holland, Dent. Mater. 8 (1992) 241

[18] C.M.A. Brett, I. Muresan, Key Eng. Mat. 230-232 (2002) 459.

[19] C.M.A. Brett, I. Ioanitescu, F. Trandafir, submitted for publication.

[20] V.W.H. Leung, B.W. Darvell, J. Dentistry 25 (1997) 475.

[21] J.Y. Gal, Y. Fovet, M. Adib-Yadzi, Talanta 53 (2001) 1103. 
[22] K. Elagli, M. Traisnel, H.F. Hildebrand, Electrochim. Acta 38 (1993) 1769.

[23] M.B. Poduch-Kowalczyk, M. Marek, E.P. Lautenschlager, Dent. Mater. 15 (1999) 397.
[24] R.G. Keanini, J.L. Ferracane, T. Okabe, Metall. Mater. Trans. B 32 (2001) 409

[25] G. Sanna, M.I. Pilo, P.C. Piu, N. Spano, A. Tapparo, G.G. Campus, R. Seeber, Talanta 58 (2002) 979. 